\title{
O Brasil na crise das ilhas Chincha: a atuação diplomática de Francisco de Varnhagen (1864-1866) ${ }^{1}$
}

\author{
Brasil en la crisis de las islas Chincha: la actuación di- \\ plomática de Francisco de Varnhagen (1864-1866)
}

\author{
Brazil in the Chincha islands crisis: Francisco \\ de Varnhagen's diplomatic performance (1864-1866)
}

\author{
José Augusto Ribas Miranda²
}

\begin{abstract}
Resumo: Este artigo analisa a atuação do diplomata brasileiro Francisco Adolfo de Varnhagen durante a crise das ilhas Chincha, que colocou Espanha contra Peru, Chile, Equador e Bolívia entre os anos de 1864 e 1866. A atuação de Varnhagen demonstra o posicionamento dúbio da chancelaria brasileira ante a conflitos entre vizinhos sulamericanos e potências europeias, ilustrando as inseguranças da política externa brasileira entre a Europa e a América. Varnhagen contrariou as disposições essencialmente neutras do Itamaraty, soltando notas de apoio aos vizinhos sul-americanos, e foi repreendido por isso. $\mathrm{O}$ artigo lança mão de extensa documentação diplomática brasileira e fornece novas perspectivas para entender este conflito importante na historiografia peruana, chilena e espanhola.
\end{abstract}

Palavras Chave: Diplomacia, América do Sul, Varnhagen, Política Externa.

Resumen: Este artículo analiza la participación del diplomático brasileño Francisco Adolfo de Varnhagen durante la crisis de las islas Chincha que enfrentó a España con Perú, Chile, Ecuador y Bolivia entre los años 1864-1866. La participación de Varnhagen da cuenta del dudoso posicionamiento de la cancillería brasileña frente a un conflicto que involucró países sudamericanos vecinos y potencias europeas, lo que ilustra las contradicciones de la política externa de Brasil en el ámbito de las relaciones diplomáticas que involucraban a Europa y América. Varnhagen contradijo las disposiciones de neutralidad dispuestas por Itamaraty, al enviar notas de apoyo a los vecinos sudamericanos, lo que le valió ser reprendido. El artículo recurre a la extensa documentación diplomática brasileña y ofrece nuevas perspectivas para entender un conflicto de gran importancia para la historiografía peruana, chilena y española.

Palabras clave: Diplomacia, América del Sur, Varnhagen, Política externa.

DOI: $10.24215 / 23142766 \mathrm{e} 088$

${ }^{1}$ Recibido 17/09/2019. Aceptado 23/10/2019.

${ }^{2}$ Doctor en História Iberoamericana por la Pontifícia Universidade Católica do Rio Grande do Sul - Brasil. Profesor Asistente Ibmec Business School - Rio de Janeiro- Brasil. joseribas50@hotmail.com 


\begin{abstract}
This paper analyzes Brazilian diplomat Francisco Adolfo de Varnhagen's performance during the crisis on the Chincha islands, which entailed the confrontations between Spain and Peru, Chile, Ecuador and Bolivia from 1864 to 1866. Varnhagen's participation shows Brazil's Foreign Affairs Office's dubious position within a conflict involving neighboring South American countries and European powers, exemplifying the contradictions of Brazilian foreign policy in the field of diplomatic relations between Europe and America. Varnhagen went against the neutrality provisions set forth by Itamaraty, by sending support notes to the South American neighbors, which caused him to be reprimanded. This paper makes use of the vast number of Brazilian diplomatic documents and offers new perspectives to understand a very significant conflict for the Peruvian, Chilean and Spanish historiographies.
\end{abstract}

Key words: Diplomacy, South America, Varnhagen, Foreign policy.

Os diplomatas nestes longínquos países não podem eximir-se de ser zeladores da observância dos princípios do direito internacional; nem considerar-se autômatos alheios aos deveres da humanidade, e filantropia. ${ }^{3}$

Francisco Adolfo de Varnhagen, 1865.

Em 7 de abril de 1864, Francisco Adolfo de Varnhagen, então ministro residente do Império do Brasil para as repúblicas do Peru, Chile e Equador, dava ciência ao Rio de Janeiro das tensões em águas peruanas, com a presença de uma esquadra do reino de Espanha sob a liderança do general Luís Hernández Pinzón. Em 27 do mesmo mês, Varnhagen noticiava a ocupação das ilhas Chincha, do Peru, por parte da esquadra espanhola. Este episódio deflagrou um conflito que perdurou por dois anos (1865 a 1866) além de um ano de tensas negociações e delicados arranjos diplomáticos (1864).

O então ministro residente do Brasil nas repúblicas do Pacífico acompanhou de perto o desenrolar da crise. Varnhagen mudou-se de Lima para Santiago quando as tensões colocaram o Chile contra a Espanha em setembro de 1865, perplexo com o bombardeio de Valparaíso em 31 de março de 1866 e com o combate de Callao, no Peru, em dois de maio do mesmo ano. Assim, este artigo analisa a atuação de Varnhagen como representante brasileiro durante o episódio e a contradições entre as diretrizes do Ministério e do diplomata, assim como os resultados prático para a política externa do Brasil na região. As disposições essencialmente neutras do governo imperial para a questão foram interpretadas pelo diplomata de modo diferente, rendendo-lhe críticas de seus superiores e de historiadores. Varnhagen atuou de modo coerente para a diplomacia do período, acompanhando as decisões dos corpos diplomáticos nas repúblicas, sendo esta participação, etiqueta do período e proceder corrente, reprovada pelo governo imperial.

\footnotetext{
${ }^{3}$ Carta ao Ministro José Antônio Saraiva. Valparaíso, 30 de dezembro de 1862 (Varnhagen, 1961: p.304)
} 
Este artigo irá apresentar o contexto geopolítico latino-americano no período da crise das ilhas Chincha. Os medos de uma "monarquização" das repúblicas sul-americanas por potências europeias foi o pano de fundo para a formação de uma aliança quádrupla entre Peru, Chile, Bolívia e Equador ante aos ataques da marinha espanhola em 1864, em que a atuação do Brasil se deu de modo delicado devido ao seu modelo monárquico. É neste cenário de crises e atropelos diplomáticos que a atuação de Varnhagen ganha importância para a análise da lenta reorientação da política externa imperial, com maior atenção às Américas. Assim, a atuação de Varnhagen e os resultados obtidos por ele e pelo Império serão analisados por meio de três distintas fases do conflito, nomeadas pelos generais/almirantes espanhóis no encargo da esquadra: Fase (Luís Hernández) Pinzón: chegada da esquadra espanhola em águas peruanas e as primeiras desinteligências, culminando com a ocupação das ilhas Chincha. Fase (José Manuel) Pareja: assinatura do tratado de paz entre Espanha e Peru, a subsequente revolução deste país e a entrada do Chile na crise. Fase (Casto) Méndez y Nuñez: declaração de guerra de Chile, Peru, Equador e Bolívia a Espanha, bombardeio do porto chileno de Valparaíso, combate no porto peruano de Callao e a retirada da esquadra espanhola.

Por fim, será realizado um balanço da atuação de Varnhagen, analisando as críticas à sua atuação e seu posicionamento ante a elas, utilizando o contexto do conflito e da diplomacia brasileira no período e a documentação produzida por sua legação para balizar a questão, demonstrando suas percepções de elementos importantes do conflito como as questões de prestígio, e a sua colaboração para a mudança na orientação da diplomacia brasileira.

\section{A década de $\mathbf{1 8 6 0}$ e as intervenções europeias nas Américas.}

O raiar das independências na América Latina assistiu ao surgimento de dois modelos políticos distintos. Por um lado, a grande maioria das ex-colônias espanholas adotou o sistema republicano robustecido pelo exemplo bem-sucedido dos Estados Unidos, em uma variada gama de disposições locais. Por outro lado, a monarquia tropical brasileira despontou, carregando laços indeléveis com sua ascendência lusa. Do surgimento das nações na América ibérica, Ansaldi (2003) destaca quatro correntes que orientaram a formação dos Estados pós-coloniais: repúblicas com notável descentralização e forte peso dos poderes locais (Peru, Grã-Colômbia, Equador); outras com a gradual erosão dos poderes locais em prol de um sistema centralizado e formalmente federalista (Argentina, México, Venezuela); outros com primazia inicial do poder central (Chile, Paraguai), além do modelo Brasileiro, que segundo o autor contou com um reforço gradual do poder central por causa e apesar do reforço dos poderes locais em uma fórmula sutil e equilibrada entre um e outro (Ansaldi 2003: p.419).

O espectro político antagônico, Repúblicas e Monarquias, encontrou nas Américas um amplo espaço de experiências. A guerra civil nos Estados Unidos (1861-1865) promoveu um lapso de ação da Doutrina Monroe no continente americano, permitindo espaços de ações para as monarquias europeias. Não que a doutrina fosse absoluta em fechar o continente americano às intervenções externas, mas a ausência de um dos principais atores apresentou-se convidativa para um novo cenário político protagonizado na década de 1860 . 
Neste período, diversos episódios conflitantes descortinaram esta tensão, criando um quadro de solidariedade entre os espíritos republicanos nas nações hispânicas, e um certo isolamento diplomático da monarquia brasileira. As acusações de "monarquiazação" feitas contra o Império do Brasil povoavam o imaginário das repúblicas vizinhas, bem como o temor de uma aliança anti-império, que delineava um cenário complexo nas relações interamericanas, opondo o modelo monárquico-luso-escravista aos diversos modelos hispanorepublicanos (Santos, 2004).

Anteriores à invasão espanhola às ilhas Chincha, dois episódios marcaram a década de 1860 e exaltaram os ânimos das repúblicas latino-americanas ante a um possível projeto de derrubada do modelo republicano. Estes episódios funcionaram como mote para os debates sobre segurança internacional travados na Conferência de Lima de 1864 bem como para a ação conjunta das repúblicas sul-americanas ante à invasão de uma monarquia europeia em águas americanas.

O primeiro episódio foi a temporária anexação de Santo Domingo (atual República Dominicana) à Espanha em 1861. Separado do Haiti em 1844, Santo domingo amargou 16 anos de guerras civis e negociações com gabinetes europeu e norte-americano. Após flertar com um protetorado francês sobre a ilha em 1846, então presidente Buenaventura Baéz negociou novamente, dessa vez com os Estados Unidos, por uma anexação em 1853. Após um golpe executado por correligionários pró Espanha, o novo presidente Pedro Santana negociou com o gabinete conservador espanhol de Isabel II uma anexação ao império esperando integrar a burocracia imperial como governador. Com apoio logístico dos governadores de Cuba e Porto Rico, Santo Domingo foi anexado em 1861.

Os quatro anos de anexação ao Império espanhol foram de intensas guerrilhas e gastos excessivos pela coroa. $\mathrm{O}$ estado deplorável dos campos e florestas dominicanas, aliados à população esparsa e pouco engajada em atividades exportadoras transformou Santo Domingo em um lamaçal político e fiscal. Em jogo, o prestígio da monarquia espanhola ante as constantes disputas imperiais europeias. Em 1864, após três governadores coloniais e nove mil baixas, a Espanha cedeu e Santo Domingo voltou ao status de nação independente. (Eller, 2017)

O segundo episódio foi a intervenção do consórcio entre Inglaterra Espanha e França no México em 1861 com a conseguinte implantação do Habsburgo Maximiliano II como Imperador mexicano. Como casus belli, o consórcio afirmava legítima a intervenção tendo em vista as dívidas não pagas pelo governo mexicano desde as lutas da independência. Aproveitando a instabilidade durante as guerras civis sob o governo de Benito Juárez, os exércitos franceses de Napoleão III invadiram o país em outubro de 1861.

Maximiliano, príncipe austríaco da casa dos Habsburgo assumiu o poder, constituindo um Império em 10 de abril de 1864. Maximiliano tentou atrair o apoio dos liberais, encetando uma série de reformas e constituindo seu gabinete exclusivamente com estes. Entretanto, o apoio que esperava com suas medidas liberalizantes não se concretizou. $\mathrm{O}$ apelo patriótico, até mesmo entre os conservadores, não permitiu o assentamento da instituição monárquica (Banzat, 1991: p.142), e o Império Mexicano fiava-se apenas na ocupação militar francesa. Em 1866 Napoleão III retira suas tropas do território mexicano, deixando Maximiliano à sua própria sorte. De fato, o príncipe Habsburgo seria executado em 19 de junho de 1867, como representado no quadro "A Execução de Maximiliano" de Édouard Manet (1867). 
Estes episódios deram o tom da geopolítica sul-americana da década de 1860 . As intervenções europeias, percebidas também como monárquicas, motivaram a união das repúblicas sul-americanas no episódio das ilhas Chincha e colocaram o Império do Brasil em posição difícil. O príncipe Maximiliano era primo de D. Pedro II, Imperador do Brasil, e as disposições neutras do Império durante a intervenção no México tampouco agradaram seus vizinhos republicanos. Assim, a atuação de Varnhagen durante o conflito entre Espanha e a quadrupla aliança enfrentou problemas de identificação institucional que, por vezes, colocou o próprio diplomata contra as disposições da chancelaria no Rio de Janeiro.

As próximas seções abordarão a crise das ilhas Chincha e como Varnhagen e a chancelaria brasileira lidaram com esse delicado momento político sul-americano, lançando mão de fontes diplomáticas brasileiras, bem como de documentos da marinha espanhola e da imprensa peruana e chilena. Ao final, a atuação de Varnhagen será discutida para um balanço da política externa brasileira para as repúblicas do Pacífico.

\section{Fase Pinzón.}

Em 1862 Isabel II, rainha de Espanha, aprovou o envio de uma expedição científica às águas do Pacífico. A frota naval composta por duas fragatas e duas galeotas era encarregada de conduzir uma expedição de cientistas pela costa sul-americana, capitaneada pelo general D. Luis Hernández Pinzón. ${ }^{4}$ A presença de embarcações militares coadunava com outros propósitos do governo espanhol, dentre eles fazer-se presente nas águas do Pacífico, com sua recente e poderosa esquadra naval, adquirida entre os anos de 1840 e 1860 no intuito de exibir prestígio e prestar apoio a súditos espanhóis nas repúblicas hispano-americanas (Rodriguez 2003: 22-23)

A expedição científica espanhola suscita controvérsias na historiografia espanhola e peruana. Autores como Pedro de Novo y Colson (1882) e José Garcia Martinez (1987/1990) percebem a expedição como fundamentalmente científica, algo corrente entre os império europeus do século XIX como demonstração de prestígio. ${ }^{5}$ Já autores peruanos como Jorge Basadre (1998) e Juan del Campo Rodríguez (2003) colocam a expedição como uma desculpa espanhola para perfilar sua recente e poderosa frota naval pelas ex-colônias, buscando uma reinserção de Espanha no cenário americano, como ocorrido em Santo Domingo em 1861 e em México em 1864. De todo modo, a esquadra espanhola de fato desencadeou uma série de eventos internacionais, acidentalmente ou não.

A presença da esquadra espanhola nas águas do Pacífico deu-se alguns meses após um episódio violento entre súditos espanhóis, contratados para trabalhar na fazenda algodoeira de Talambo, no Peru, e os donos da fazenda, peruanos. A Riña de Talambo

\footnotetext{
${ }^{4}$ A esquadra era formada pelas fragatas Resolución e Triunfo e pelas galeotas Vencedora e Covadonga. A expedição científica era composta por um geólogo, um entomólogo, dois zoólogos, um botânico e um etnólogo/antropólogo (Colson 1882: p.89)

${ }^{5}$ Pedro de Novo y Colson (1846-1931), historiador e tenente de navio da marinha espanhola, escreveu uma apologética e importante obra sobre o conflito entre Espanha e as Repúblicas do Pacífico. Sua Historia de la Guerra de la España en el Pacífico foi publicada em 1882, quase contemporânea ao conflito, contendo informações técnicas, listagens, cópias de documentos e impressões fundamentais para o estudo do episódio.
} 
desembocou em um delongado processo judicial que contou com a interpelação da esquadra espanhola, presente na região às voltas com seu comitê científico. ${ }^{6}$

Com a chegada da esquadra de Pinzón ao porto de Callao em março de 1864, as notícias de Talambo alcançaram o general espanhol. No mesmo mês desembarcava também Eusébio Salazar y Mazarredo, ex-deputado das cortes espanholas e recém- nomeado ministro plenipotenciário de Espanha para a Bolívia. Salazar y Mazarredo protagonizou o estopim da crise, sendo condenado em uníssono pela historiografia de ambas as partes do conflito. ${ }^{7}$

O Peru ainda não possuía sua independência formalmente reconhecida pela Espanha e por isso Salazar y Mazarredo fora enviado à república com o título de Comisario Especial Extraordinario (Basadre, 1998: 1022). Todavia, esta nomeação causara consternações ante ao gabinete peruano, devido a este título ser utilizado para enviados espanhóis em suas colônias. A isto o diplomata brasileiro João Duarte da Ponte Ribeiro, substituindo Varnhagen temporariamente em Lima, ${ }^{8}$ relatava ao Império em 27 de abril de 1864:

Efetivamente o Sr Ribeyro designou o dia 30 daquele mês para o reconhecimento solene do Sr. Salazar e Mazarredo e só então viu que este não trazia caráter diplomático, mas sim o de Comissário especial Extraordinário, títulos que o Governo espanhol dá aos agentes que envia às suas colônias. ${ }^{9}$

Segundo Basadre, Colson e Rodriguez, as instruções de Salazar y Mazarredo eram de interceder pelos súditos de maneira pacífica, resguardando o uso da força somente para casos extremos. Entretanto, a recusa do governo peruano em recebê-lo com um título destinado a agentes coloniais levou o comissário espanhol a reunir-se com Pinzón a bordo da fragata Resolución afirmando que possuía ordens para a utilização da força, e recomendou o apresamento das ilhas Chincha, então grande produtora de guano. ${ }^{10}$

A historiografia do episódio aponta como motivos de Salazar y Mazarredo para o apresamento das ilhas Chincha um antigo sonho em adquirir recursos suficientes para a compra de Gibraltar, então de posse do Reino Unido, motivo de desprestígio para a Coroa

\footnotetext{
${ }^{6}$ O episódio da Riña de Talambo, ocorrido em 4 de agosto de 1863 na província peruana de Chiclayo, teve seu desfecho com quatro espanhóis e um peruano mortos. O processo correu por um ano nos tribunais peruanos com a absolvição do dono da propriedade e a subsequente intervenção diplomática do enviado espanhol, Salazar y Mazarredo e da esquadra espanhola comandada por Pinzón (Colson, 1882: 138; Rodriguez, 2003: 51) e (Basadre, 1998: 1024).
}

${ }^{7}$ Basadre relata que Salazar y Mazarredo era caracterizado como "enfermizo, epiléptico, locuaz, entrometido..." (Basadre, 1998: 1025); Colson também culpa o enviado espanhol, dizendo que enganara Pinzón, e que em inícios da crise era "el único hombre que habia jurado encender la guerra" (Colson, 1882 :187).

${ }^{8}$ Varnhagen encontrava-se em Santiago em arranjos de seu casamento com a chilena D. Carmen Ovalle y Vicuña como justificado em ofício de 12 de Abril de 1864. Cf. Ofício de 12/04/1864, de João Duarte da Ponte Ribeiro ao sr. Francisco Xavier Paes Barreto. Missão Varnhagen nas repúblicas do pacífico 1863-1867, Vol I, Rio de Janeiro: FUNAG, 2005,p.116. A Partir de Agora Missão Varnhagen.

${ }^{9}$ Ofício de 27/04/1864, de João Duarte da Ponte Ribeiro ao sr. Francisco Xavier Paes Barreto. Missão Varnhagen, Vol I, p. 119

${ }^{10} \mathrm{O}$ guano, excremento de aves marinhas, era utilizado como fertilizante natural na produção agrícola. Configurava como motor da riqueza peruana entre as décadas de 1840 e 1870, correspondendo a mais de $50 \%$ das exportações do Peru na década de 1860. Conferir (Tantaleán, 2011) 
espanhola. (Basadre, 1998, p. 1027; Colson, 1882, p. 187-188; Rodriguez, 2003, p. 59). Apesar de munido com instruções de uso da força apenas como último recurso, o comissário espanhol ocultara tais desígnios do general Pinzón, conduzindo-o ao aprisionamento das ilhas Chincha, mantendo reféns os 200 soldados peruanos em guarda do arquipélago.

Assim, Duarte da Ponte Ribeiro noticiava em ofício ao Rio de Janeiro a tomada das ilhas Chincha em 14 de abril de $1864,{ }^{11}$ deflagrando uma crise e subsequente conflito que perduraria até 1866.

Em 16 de abril de 1864, Pinzón e Salazar y Mazarredo enviaram uma circular ao governo peruano reivindicando a posse das ilhas Chincha como direito de represália aos maustratos sofridos pelos súditos espanhóis em Talambo. Anuía que, pela Espanha não ter reconhecido a independência formal do Peru, as ilhas guaneiras poderiam ser reivindicadas, como havia feito Reino Unido com as ilhas africanas de Fernando Pó, Annobon e Corisco. ${ }^{12}$

A utilização do termo "reivindicação" soou pesado aos governos peruano e chileno. 0 medo, ou ao menos o discurso de medo, de recolonização por parte das repúblicas do Pacífico tornou a negociação mais tensa e irresoluta. Colson, apesar de aprovar a questão reivindicativa, alertou para o fatal erro de Pinzón e Salazar y Mazarredo, que tocara fundo nas susceptibilidades peruano-chilenas:

¿Pero se hizo bien en emplear la palabra reivindicación? Fue la más grande de las imprudencias, el más inconcebible de los disparates; pues aunque alardear de un derecho no debiera encerrar nunca tanto peligro, en las presentes circunstancias equivalía a herir de uno solo golpe todos los rostros americanos, á gritarles que en Santo Domingo y Méjico hicimos conatos de reivindicación; que debían disponerse para resistir a la España de Cortés y de Pizarro (Colson, 1882: 190).

Devido a sua temporária ausência de Lima, Varnhagen não pode participar da moção de repúdio à ocupação das ilhas Chincha, realizada pelo corpo diplomático acreditado na capital, assinado pelos representantes dos Estados Unidos, Inglaterra, Havaí, Bolívia e Chile. ${ }^{13}$ Noticiava ao Rio de Janeiro, em maio do ano corrente, que nutria simpatias pela causa peruana, tendo, porém, se eximido de participar de tal moção devido à sua viagem à Santiago:

Nem as minhas convicções, nem as conveniências do serviço em relação ao necessário prestígio da Legação Imperial nesta República, me aconselhavam a deixar de testemunhar as minhas simpatias pela nação débil que conquistou sua independência e foi agora menos nobremente atacada por forças da antiga Metrópole.

Pela minha parte dou graças à Providência o ter-me dado motivos para demorar um mês mais do que pensava o meu regresso a esta Capital,

\footnotetext{
${ }^{11}$ Ofício de 27/04/1864, de João Duarte da Ponte Ribeiro ao sr. Francisco Xavier Paes Barreto. Missão Varnhagen Vol I, p. 119.

12 Idem,122-123.

${ }^{13}$ Idem, 124-125.
} 
conseguindo com isso o ter-me visto desobrigado de recusar envolver-me em um negócio que aliás tanto desprestigiou os que nele tiveram parte. ${ }^{14}$

Ainda em junho o Ministro dos Negócios Estrangeiros João Pedro Dias Vieira instruía Varnhagen a oferecer os bons ofícios, e apoio moral à causa americana, caso as disposições de Pinzón e Salazar y Mazarredo não fossem endossadas pela Coroa espanhola. ${ }^{15}$ O governo de Madri não havia recomendado a invasão das ilhas, apenas a utilização de força como último recurso. A ação de Pinzón, sob as instruções de Salazar y Mazarredo, pegaram o governo espanhol de surpresa. A atitude do comissário fora desaprovada pelo novo primeiro ministro espanhol José Maria Narváez, que o destituiu do cargo, tendo regressado à Espanha ainda em maio (Rodriguez, 2003: 67)

Assim, a reação pró-Peru tomada pelo governo imperial encontrava explicação na medida em que as disposições da esquadra não eram as mesmas do governo. Deste modo, a manifestação de simpatia de Varnhagen e o posicionamento inicial do Rio de Janeiro não suscitariam constrangimentos no governo espanhol.

Todavia, ao regressar à Espanha, Salazar y Mazarredo acusara o governo peruano de tentativa de assassinato durante sua viagem, tornando a situação, que então acenava para um arranjo, mais turbulenta. Com as novas notícias, a Coroa espanhola passara a endossar as ações de Pinzón, culminando com o envio de mais três embarcações para o reforço da esquadra do Pacífico (Colson, 1882, p. 202).

Com o endosso do governo espanhol , o tom do governo imperial também mudara. Passara agora a declarar-se neutro e a oferecer os bons ofícios no intuito colaborar com o fim da desinteligência, como exposto no relatório do Ministério dos Negócios Estrangeiros relativo ao ano de 1864 :

Como resposta limitou-se também o governo imperial a declarar que sinceramente lamentava os factos em questão, e fazia votos para que cessassem quanto antes a bem da paz e do progresso da civilização os motivos, que tinham vindo perturbar as relações de amizade existentes entre o Peru e a Espanha. ${ }^{16}$

Santos, (2002) afirma que o Brasil adotou uma postura neutra durante todo o conflito, porém deixou de observar as primeiras reações em favor do Peru, devido aos atos dos representantes espanhóis ferirem o decoro político internacional por não apresentarem endosso do governo. Assim, com as disposições claras, pôde o governo manifestar sua neutralidade de maneira oficial.

\footnotetext{
14 Ofício de 27/05/1864, de Francisco Adolfo de Varnhagen ao sr. João Pedro Dias Vieira. Missão Varnhagen Vol I, p. 128-129.

15 Despacho de 07/06/1864, de João Pedro Dias Vieira ao sr. Francisco Adolfo de Varnhagen. Missão Varnhagen, Vol I, p. 263-264.

${ }^{16}$ Relatório da Repartição dos Negócios Estrangeiros. 1865, p.38.
} 
Em dezembro de 1864 o general Pinzón fora substituído pelo almirante José Manuel Pareja, que passaria a conduzir as negociações da esquadra espanhola, sendo nomeado ministro plenipotenciário de Espanha para o Pacífico (Colson, 1882: 245).

As observações de Varnhagen foram importantes para a compreensão das forças profundas subjacentes no episódio. Além das questões pessoais e de honra, o diplomata brasileiro apercebia-se da escalada de hostilidades no Pacífico devido à tentação de um apresamento tão fácil das desguarnecidas ilhas guaneiras:

Para mim é, entretanto, fora de dúvida que Pinzón e Mazarredo se deixaram arrastar pelos instintos de vingança contra o gabinete de Lima, e especialmente contra o Ministro Ribeiro, de que se achava possuído o Encarregado de França Lesseps, que a seu bel prazer soube manejar ambos. Também p. a o meu espírito é fora de toda a dúvida que os comissários espanhóis não pensaram nunca em provocar a seu país uma luta duradoura e só sim aproveitar-se da surpresa e desconcerto em que imaginaram colocar o Peru, no momento de priva-lo do seu tesouro, na ansiedade de reaver este, submeter-se a todas as exigências; ${ }^{17}$

Esta percepção do apresamento fácil de tão rendoso recurso como arma de negociação coadunaria com os já citados objetivos de Salazar y Mazarredo, em adquirir meios suficientes para readquirir Gibraltar para a Espanha e com as ações espanholas no plano internacional durante o período de Isabel II.

A invasão das ilhas Chincha estava inserida em um cenário de reaquisição de prestígio do reino de Espanha, iniciado na década de 1840. A construção de uma grande e moderna frota naval sob o reinado de Isabel II permitiu ao reino impor sua presença em terras distantes, ao mais clássico estilo da política canhoneira oitocentista. Intervira no Marrocos e Venezuela em 1859, conseguindo concessões duras por meio de tratados desiguais (Pereira, 2010), além da intervenção no México em 1864 para garantir o pagamento de débitos, e de sua presença reforçada no Caribe, com a reanexação de Santo Domingo, como descreveu o espanhol Colson de que "debieran apercibirce los dominicanos de que en España se nubla a menudo la sensatez, cuando insistieron y al fin lograron a princípios de 1861 el que les fuera aceptada la suspirada anexación." (Colson, 1882, p. 67)

A escalada das hostilidades, partindo da posse desautorizada das ilhas Chincha por Pinzón até a mudança no tom das conversações, com o envio do almirante Pareja fora acompanhada por Varnhagen. Em ofício de quatro de junho de 1864 ele noticiava ao Rio de Janeiro:

A plebe ocupa-se em escrever e ler comunicados nos jornais contra o Almirante Pinzón, os literatos em publicar versos contra a Espanha, os políticos noveleiros em assoalhar boatos de mudança no Ministério, e todos creem que, sem expor-se a grandes perigos, as ilhas Chincha hão de volver ao

\footnotetext{
${ }^{17}$ Ofício de 22/08/1864, de Francisco Adolfo de Varnhagen ao sr. João Pedro Dias Vieira. Missão Varnhagen Voll, p. 153.
} 
domínio da República. ${ }^{18}$

Em setembro Varnhagen já percebia o endurecimento nas negociações, prevendo maiores hostilidades:

A questão hipano-peruana não adianta um passo: porém a Espanha achase metida em outras dificuldades. E provavelmente só anela a que se lhe apresente uma ponte fácil para poder passar sem desonra. A notícia de que o Chile também se armara e comprava na Europa barcos de guerra produzira na Granja grande sensação. ${ }^{19}$

O ministro brasileiro estava ciente também das questões subjetivas envolvidas no conflito: a honra e o prestígio nas exigências de Pinzón e na resistência peruana em negociar, apesar de não constituírem a pedra angular da querela, davam o tom do desarranjo. Raymond Aron em Paz e Guerra entre as Nações (2002) analisa as questões de glória e prestígio nas relações internacionais, que poderiam tomar grandes proporções. Expondo a presença do fator de prestígio Aron afirma:

Dir-se-á talvez que a glória é apenas um outro nome ou um aspecto da potência reconhecida pelos outros, cuja fama se alastra pelo mundo. Num certo sentido, esta objeção é válida, e os três objetivos que mencionamos podem ser reduzidos a dois: ou as unidades políticas buscam segurança e força, ou procuram ser respeitadas, impondo sua vontade e recolhendo os louros que cabem ao vencedor. Um desses objetivos seria material (força); o outro seria moral, inseparável do diálogo humano - definível pela grandeza, consagrado pela vitória e a sujeição do inimigo (Aron, 2002: 130).

A questão do prestígio apresentava-se não somente pelos comissários espanhóis ou ministros peruanos, mas era parte importante também na relação entre os Estados, e o percurso espanhol durante o reinado de Isabel II juntamente com os argumentos utilizados pelos negociadores corroboram com esta perspectiva. Não é ignorável que os arranjos entre Espanha e Peru ao longo da crise deixaram de ser firmados duas vezes por se discutir quem soaria os primeiros cañonazos de salve-bandeira. ${ }^{20}$

Varnhagen perdera as esperanças em qualquer espécie de mediação por parte do Brasil, notando que o conflito tomara proporções irremediáveis:

A questão deste país com a Espanha segue no mesmo estado. Devo porem informar a V.Exa que começo a perder a esperança de que possa ser

\footnotetext{
${ }^{18}$ Ofício de 04/06/1864, de Francisco Adolfo de Varnhagen ao sr. João Pedro Dias Vieira. Missão Varnhagen Vol I, p. 136.

19. Idem, p.178. Grifos meus.

${ }^{20}$ Os cañonazos, tiros de canhão de função simbólica, compunham parte da etiqueta das marinhas no século XIX como demonstração de respeito à dignidade nacional entre as embarcações representantes dos governos.
} 
profícua qualquer mediação estranha se Ella não for acompanhada de alguma indicação habilmente insinuada ao Gabinete de Madrid [... $]^{21}$

A mudança das disposições do gabinete espanhol- da reprovação ao apoio- às ações da esquadra no pacífico podem ser analisadas à luz da eficácia dos grupos reais de decisão,22 trabalhados por Jean-Baptiste Duroselle (2000). Para o autor francês, as decisões em política internacional estão atreladas aos grupos reais. Como no caso da crise das ilhas Chincha, as decisões espanholas partiram de um grupo real composto por Pinzón e Salazar y Mazarredo, e foram endossadas por outro grupo, o gabinete de Madri. Aí está em jogo, para a tomada de decisão, o conjunto de valores subjacente às vivências e experiências de tais grupos reais, em que se formula uma concepção de interesse nacional, como afirma o autor:

O chefe, sendo uma única pessoa (o caso é mais complicado quando se trata de um pequeno grupo), tem uma certa concepção de interesse nacional, ligada à sua própria escala de valores. Ele deduz os objetivos ideais que deseja alcançar e, desses objetivos ideais, em função do "resto", ele tirará os objetivos acessíveis. Tudo isso, evidentemente, está ligado à sua personalidade consciente e até mesmo inconsciente (Duroselle, 2000: 232-233)

As questões de honra e glória, de que fala Aron, por parte dos enviados espanhóis, e as questões do prestígio da Coroa espanhola formavam a rede de interesses nacionais e a hierarquia de valores da ação espanhola no Peru. Na base, as questões pecuniárias, como apresamento de tão valioso butim e possíveis recursos para a reaquisição de Gibraltar. Na superfície, as delicadas relações de honra e prestígio. Além dos possíveis benefícios econômicos que poderiam advir do apresamento das ilhas guaneiras, sua posse funcionava também como recurso argumentativo para vencer no debate pela glória da esquadra no Pacífico e do prestígio espanhol, em busca de ascensão no período isabelino. ${ }^{23}$

As impressões de Varnhagen sobre o conflito contribuem, de forma significativa para a compreensão do conflito. Ele transitava entre os ditos grupos reais - espanhóis, peruanos e dele próprio, brasileiro - montando um quadro analítico das reações às negociações, desvelando motivos pecuniários subjacentes e os de prestígio e honra à superfície.

\section{Fase Pareja}

A substituição de Pinzón por Pareja em dezembro de 1864 foi acompanhada pelo endurecimento das negociações por parte de Madri e por mais três embarcações de guerra.

\footnotetext{
${ }^{21}$ Ofício de 01/10/1864, de Francisco Adolfo de Varnhagen ao sr. João Pedro Dias Vieira. Missão Varnhagen Vol l, p. 182.

22 Para seu estudo sobre as relações internacionais, Duroselle apresenta seu conceito de Grupos Reais. Seriam estes grupos "instituídos segundo a escolha e a preferência de seus membros", como os grupos diretivos de um Estado ou, no caso deste estudo, da esquadra espanhola no pacífico, e deles emanariam as instancias reais na tomada de decisões. Conferir em (Duroselle, 2000).

${ }^{23}$ Colson afirma que nenhum benefício pecuniário foi angariado pela Espanha pela posse das ilhas Chincha, reforçando o argumento de que se as questões de prestígio também se constituíam relevantes para ambas as partes da querela (Colson, 1882: 191)
} 
As questões de prestígio ocupavam então uma importante pauta nas reclamações, em uma tentativa de ofuscar aparentes interesses pecuniários e políticos, como encetados no Marrocos e Venezuela seis anos antes. O governo espanhol instruía Pareja sobre os principais pontos da questão com o Peru:

V.E no ignora que el principal interés que tiene la cuestión pendiente entre España y el Perú es de honra y de dignidad nacional. Todas las demás cuestiones que atañen à derecho, ya del Estado, ya de particulares son de importancia secundaria ante la imprescindible de vindicar el honor ultrajado de nuestra bandera y de reconquistar el respeto debido à nuestro decoro[...] (Colson, 1882: 251)

No mesmo mês, o Congresso Americano em Lima buscava mediar a situação. ${ }^{24} \mathrm{~A}$ nota enviada pelos ministros plenipotenciários em Lima compunha a segunda tentativa de um corpo diplomático nesse sentido. No manifesto, afirmavam ser a causa não somente peruana, mas americana, colocando um possível alinhamento dos Estados assinantes caso as hostilidades continuassem. ${ }^{25}$ Varnhagen não tomou parte no abaixo assinado, utilizando argumentos "que foram bem aceitos, me deixando bem com este Governo [Peru]", ${ }^{26}$ além de ter argumentado que não estava oficialmente acreditado no Congresso Americano.

Pareja recusou negociar com o Congresso, afirmando ter instruções para tratar somente com o governo peruano. Varnhagen relatava que embora ambas as partes fossem afeitas a uma saída diplomática, a Espanha não aceitaria condições que considerasse humilhantes:

Sabe-se geralmente que o atual Gabinete se acha possuído dos melhores desejos para entrar em ajustes; mas não é dado a crer que se humilhe a passar pelas forças caudinas de aceitar, sem que sofram alguma modificação, as condições propostas em Junho pelo Ministro Pacheco ao Cônsul Moreira e rechaçadas por este governo. ${ }^{27}$

Pareja enviou um ultimatum ao governo peruano, ameaçando com bombardeios à costa da república, caso as negociações não frutificassem. O presidente Pezet enviou o general Manuel Ignácio de Vivanco às ilhas Chincha para uma negociação derradeira. Foi então assinado em 27 de janeiro de 1865 o tratado Vivanco-Pareja e cessadas as hostilidades.

A repercussão negativa do tratado no Peru originou um movimento revolucionário na província de Arequipa, encabeçada pelo general Mariano Ignácio Prado. Prado alardeara as condições humilhantes impostas pelo tratado, concluindo que este somente formalizara a

\footnotetext{
${ }^{24}$ Em 1864 Lima sediou o Congresso Americano, reunindo Peru, Chile, Equador, Bolívia, Venezuela, Nova Granada e EL Salvador como países Signatários. Brasil e Argentina participaram como observadores. O Congresso deliberou sobre questões de segurança internacional, delimitação de fronteiras e conflitos como o recente entre Espanha e os signatários sul-americanos. Sobre as negociações do congresso conferir Miranda, 2013 capítulo três.

${ }^{25}$ Ofício de 18/02/1865, de Francisco Adolfo de Varnhagen ao sr. João Pedro Dias Vieira. Missão Varnhagen Vol I, p. 357-364.

${ }^{26}$ Idem, p. 329.

${ }^{27}$ Idem, p. 230.
} 
sujeição do Peru às pretensões espanholas (Rodriguez, 2003: 108) O Tratado Vivanco-Pareja previa a devolução das ilhas Chincha em favor do direito de reivindicação, o futuro reconhecimento do Peru pela Espanha com pagamento de dívidas oriundas das guerras de independência e mais um pagamento de três milhões de pesos à Espanha por gastos com a manutenção da esquadra no pacífico

Sobre a demanda por indenizações, Varnhagen relatava que apesar das questões de honra e dignidade nacional aparentemente ocupassem um primeiro plano, a quantia exigida por Pareja, inserida no tratado por sua iniciativa, sem respaldo oficial, ${ }^{28}$ cobririam largamente os gastos realizados pela esquadra, não sem prejuízos à imagem da Espanha para suas ex-colônias:

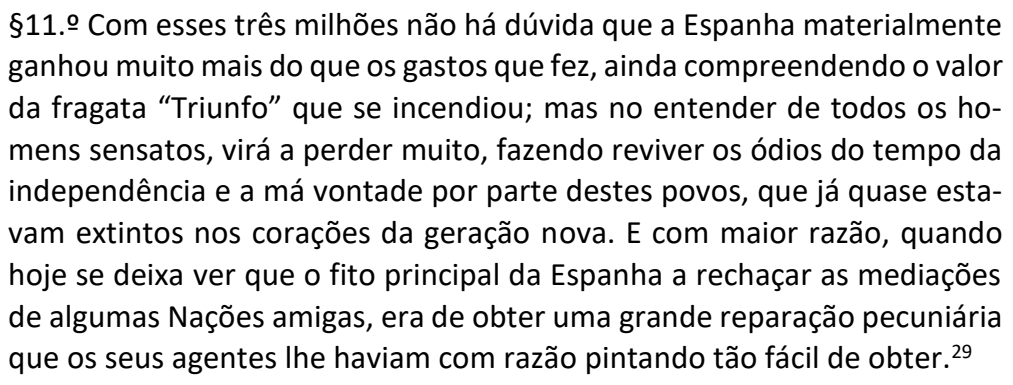

Enquanto a revolução se dava no Peru, o governo chileno havia declarado contrabando de guerra a venda de carvão às embarcações espanholas(Colson, 1882: 218). Este ato levou Pareja a enviar sua esquadra às águas chilenas, buscando reparações diplomáticas ante a quebra de neutralidade com tal declaração. As exigências consideradas humilhantes do tratado com o Peru levaram o Chile a tais hostilidades, temerosos de uma possível imposição destes termos para si. Com a frota estacionada no imenso litoral chileno-peruano, o carvão de pedra, essencial para a locomoção das fragatas a vapor, e os víveres para a tripulação seriam dificilmente adquiridos. Em setembro de 1865, Pareja declarou bloqueados os portos do Chile em represália às ações hostis, enviando um ultimatum com a exigência de um pedido formal de desculpas e 21 cañonazos de salve-bandeira. Em resposta, o Chile declarou guerra à Espanha (Burr, 1974: 97)

Varnhagen estava atento a essa movimentação. Em oficio de nove de setembro, antes da declaração oficial de guerra do Chile, previa que a reação chilena seria mais dura que a do Peru do presidente Pezet:

Como o Chile não se ressente da principal causa das debilidades desta República; isto é, de ter o seu tesouro (as Chinchas) em uma ilha à mercê de

\footnotetext{
${ }^{28}$ Segundo Colson, Pareja incluira a indenização no tratado contra as disposições do gabinete de Madri, que diziam que "No exigirá V.E indeminización alguna por los gastos de la expedición en el caso de que tengan las negociaciones um deselnance pacífico" (Colson, 1882: 259). A indenização foi um dos grandes motivos para o fracasso do tratado, que levaria à revolução de Arequipa com a mudança no governo peruano, a entrada formal do Chile na crise e a subsequente guerra. Uma aposta demasiadamente alta que o gabinete espanhol não previa mas teve de levar adiante.

${ }^{29}$ Ofício de 04/02/1865, de Francisco Adolfo de Varnhagen ao sr. João Pedro Dias Vieira. Missão Varnhagen, Vol I,p. 327.
} 
qualquer esquadra, e como aí o carácter natural do povo é essencialmente belicoso e arrogante, não deixa de ser para recear que sobrevenha entre essa República e a Espanha uma questão muito mais grave e duradoura do que ultimamente saiu o Perú. ${ }^{30}$

Varnhagen se mudou para o Chile no intuito acompanhar de perto o desencadear do conflito. Ao chegar em Valparaíso, em 7 de outubro, avistou a esquadra de Pareja em frente ao porto. ${ }^{31}$ Também relatou a reação do corpo diplomático acreditado no Chile, que buscou uma mediação para evitar o rompimento das relações. Acompanhando o corpo diplomático, Varnhagen enviara um ofício à Pareja lamentando o rompimento das relações para com o Chile. Protestava contra o bloqueio, alertando para os prejuízos sofridos por súditos brasileiros e de demais nações neutras. Também lembrava Pareja da dificuldade de se bloquearem os 31 portos do Chile com uma esquadra de dimensões moderadas. ${ }^{32}$

A manifestação de Varnhagen foi recomendada e celebrada pelo decano do corpo diplomático em Santiago, cônsul americano Thomas Nelson. O ministro brasileiro juntou-se aos demais diplomatas de países também neutros como Itália, Prússia, Inglaterra, França em uma nota de protesto em finais de setembro. A nota, redigida pelo representante dos Estados Unidos, afirmava que o conflito não visava conquistas materiais, mas somente de honra, comumente resolvidas em mediações pacíficas. Também afirmava que a mesma nota seria enviada ao ministro das relações exteriores do Chile, Álvaro Covarrubias, no intuito de cessar as hostilidades. ${ }^{33}$ Pareja recusou novamente qualquer tipo de mediação, afirmando que "[...] la nación que ha sido injuriada, que ha recibido ofensas del carácter de las hechas à España por Chile, no puede en manera alguna, sin comprometer su honra, sin menoscabar su dignidad, dejar de ser juez propio[...]"34

A reação do governo imperial foi dura. Temendo uma quebra de neutralidade o ministro Saraiva admoestou severamente Varnhagen afirmando que se a nota não era hostil à Espanha, não deixava de ser favorável ao Chile. Em seguida advertia-o:

Estou certo de que V.S. compreende que o Representante do Brasil deve conservar-se em perfeita neutralidade enquanto o contrário não lhe é ordenado; mas os seus sentimentos particulares manifestaram-se, mau grado seu, em forma oficial. Por isso não me cabe a satisfação de dizer-lhe que é inteiramente aprovado seu procedimento.

Queira V.S. ter sempre presente esta recomendação. ${ }^{35}$

\footnotetext{
${ }^{30}$ Ofício de 05/09/1865, de Francisco Adolfo de Varnhagen ao sr. José Antônio Saraiva. Missão Varnhagen Vol I, p. 421.

31 Idem, 439.

32 Idem, 442.

33 Idem, 450.

${ }^{34}$ Idem, 452.

${ }^{35}$ Despacho de 22/11/1865, de José Antônio Saraiva ao sr. Francisco Adolfo de Varnhagen. Missão Varnhagen Vol I, p. 442.
} 
Há uma série de questões envolvidas neste embate entre Varnhagen e o Ministério. 1- O Brasil encontrava-se em guerra contra o Paraguai e temia que a quebra de neutralidade pudesse gerar dificuldades na condução da campanha militar. 2- A nota de Varnhagen vazara nos jornais do Rio de Janeiro, provocando consternação com os representantes espanhóis no país ${ }^{36}$ que pediram a demissão de Varnhagen. ${ }^{37}$ 3- Uma vez interpretada a manifestação de Varnhagen como pró-Chile, isto iria contra a prática diplomática do Império, sensivelmente euro-orientada. ${ }^{38}$ Ao colocar as impressões de Varnhagen como pessoais, o Ministério procurava se desvencilhar de tal manifesto, provavelmente levando em conta os laços de seu ministro com o Chile (Varnhagen era casado com uma nacional chilena) em que constantemente pedia para transferir-se de Lima para Santiago durante sua estada como ministro residente.

Varnhagen procurava trabalhar a imagem do Império nas repúblicas do Pacífico. Contando com o crédito pessoal acumulado em 11 anos de atuação na Espanha, ele se propôs a interpelar a questão na segurança da companhia de seus colegas do corpo diplomático. Entre outubro e novembro, mês em que recebeu a admoestação do ministro Saraiva, Varnhagen enviou recortes de jornais e declarações do ministro chileno Covarrubias exaltando suas ações, obrando por uma melhor imagem do país na região. ${ }^{39} \mathrm{O}$ Império estava em guerra no Prata, e os pedidos para a condução de uma diplomacia de neutralidade visavam o impedimento de uma eventual participação de terceiros no conflito. ${ }^{40}$ Assim entendeu Varnhagen, e obrava para manter as relações para com repúblicas do Pacífico como recomendado: cordiais ao Brasil.

A atuação de Varnhagen acompanhou as declarações das nações mais importantes do mundo. Inglaterra, França, Itália e Estados Unidos em nota conjunta condenaram as ações de Pareja, oferecendo mediação. Varnhagen já havia se eximido da primeira nota de repúdio, em conjunto com as repúblicas sul-americanas contra Pinzón em abril de 1864. Também não participou da nota dos plenipotenciários acreditados no Congresso Americano - não por não ter tomado assento formalmente, uma vez que o enviado argentino, Domingos Faustino Sarmiento, também não tomara assento e assinou o manifesto. Ademais, em ambas as situações não havia uma declaração formal de guerra. Contra o Chile ele se manifestou, apoiado, e até mesmo ligeiramente pressionado, pelas conveniências diplomáticas de representantes de nações de tão grande calado político e naval. Novamente, as ações do diplomata brasileiro faziam sentido sob a perspectiva dos grupos reais de decisão ao não se furtar de emitir apoio à causa americana.

\footnotetext{
${ }^{36}$ Carta ao Ministro José Antônio Saraiva, Valparaíso, 30 de dezembro de 1866 (Varnhagen, 1961: 303)

37 Ofício de 14/04/1866, de Francisco Adolfo de Varnhagen ao sr. José Antônio Saraiva. Missão Varnhagen Vol II, Anexo II, p. 73.

${ }^{38}$ A orientação europeia é apresentada em Miranda (2013) e Santos (2004).

${ }^{39}$ Conferir a correspondência dos dias 23/10, 24/10, 14/11 e 24/11 de 1865 em que, sem saber ainda de sua admoestação, enviara os resultados positivos de sua interpelação junto ao corpo diplomático das nações neutras. Missão Varnhagen Vol I, p. 446-468.

${ }^{40}$ A historiografia brasileira aponta os esforços diplomáticos para a manutenção da neutralidade dos demais países da américa do sul no conflito. Conferir Bandeira (1998) e Doratioto (2002).
} 
A ausência de protesto de Varnhagen, recomendada pelo governo imperial, nas notas de repúdio contra a agressão da esquadra espanhola no Peru colaborou para um crescente quadro de animosidades entre esta república e o Império. Desde a década de 1840, com o início das negociações sobre as fronteiras amazônicas, até finais da década de 1860, as relações entre Brasil e Peru erodiram constantemente, chegando a um rompimento em 1867, quando o próprio Varnhagen pedira seus passaportes para retornar ao Brasil (Santos, 2002: 109)

No caso chileno, apesar da declaração de Varnhagen ter rendido dissabores com o Rio de Janeiro, as relações para com o Império do Brasil seguiram uma ascendente constante, chegando em vários momentos a configurar uma "aliança virtual" como colocaram Santos (2002) e Burr (1974).

A atuação de Varnhagen obedecia à lógica da prática diplomática no século XIX. As dificuldades de comunicação corroboravam para uma maior autonomia da diplomacia in loco, que possuíam maior poder de decisão e participação na política externa dos Estados (Duroselle, 2000, p. 114). Eram responsabilidades atribuídas pelo poder central. Assim, ficava ao encargo dos diplomatas a condução de grande parte das negociações, e mesmo o julgamento criterioso das decisões a serem tomadas, inseridos nos seus grupos reais de decisão. Portanto, Varnhagen agiu inserido em um contexto de maior relevância das impressões e decisões dos agentes diplomáticos, tomando para si a responsabilidade e o julgamento apropriado para a questão.

A resposta do diplomata brasileiro ao ministro Saraiva deu-se em Santiago no dia oito de janeiro de 1866. Em seu ofício Varnhagen reiterava sua posição de subordinado, apresentando, entretanto, suas justificativas:

Para não apresentar-me agora aos olhos de V.Ex como abrigando sentimentos contrários a este firme propósito em que estou, deixarei de alegar várias razões e argumentos que sem dúvida muito me desculpariam. Creio entretanto essencial não ocultar a V.Exa que a minha nota produziu em pró do Brasil mui favorável impressão nesta República e na do Perú, e que talvez com frases mais pálidas e indecisas ou com um completo silêncio (que se poderia maliciar de cumplicidade) não haveria eu conseguido destruir de uma vez e com tanta oportunidade a acusação injusta levantada aqui ultimamente, no ano passado pelos defensores do Paraguai de que o Brasil estava apoiado em certos planos europeus de monarquisar a América. ${ }^{41}$

Também afirmava que sua nota não deveria ter sido publicada, uma vez que intencionava "fazer correr, como tantas vezes se usa na diplomacia para produzir o devido efeito sem responsabilidade imediata". Terminava seu ofício reiterando que como diplomata subordinar-se-ia às disposições do Ministério, disposto a quaisquer sacrifícios para a dignidade do Império.

\footnotetext{
${ }^{41}$ Ofício de 08/01/1866, de Francisco Adolfo de Varnhagen ao sr. José Antônio Saraiva. Missão Varnhagen Vol II, p. 8.
} 


\section{Fase Méndez y Nuñez.}

No Peru, a revolução de Arequipa triunfou. O presidente Pezet foi deposto, acusado pelos insurgentes de submeter o país às mais duras humilhações pelo tratado Vivanco-Pareja. Em 28 de novembro de 1865, Mariano Ignácio Prado assumia como Jefe Supremo Provisório de la República renunciando ao pagamento da indenização prevista por Pareja declarando guerra à Espanha, em alinhamento ao Chile.

No mesmo dia, a corveta chilena Esmeralda capturou a galeota espanhola Covadonga, incendiando os ânimos de ambas as repúblicas (Rodriguez, 2003: 125). O Chile iniciara uma investida diplomática pela América no intuito de arregimentar apoio e alianças. Firmada a aliança com o Peru do jefe Prado em novembro de 1865, formalizou também uma aliança com Equador em janeiro de 1866 e com a Bolívia no mês seguinte. Formava-se a Quádrupla Aliança, que encerrou a frota espanhola em mais de 3000 milhas de portos bloqueados, impedida de adquirir víveres para a tripulação e carvão para suas embarcações (Burr, 1974: 98-99).

Após a tomada da Covadonga pelos chilenos, Pareja suicidou-se em sua cabine, sendo a esquadra assumida pelo capitão da fragata blindada Numancia, D. Casto Méndez y Nuñez. O novo comandante reduziu o bloqueio ao Chile, de quatro para um porto, concentrandose em Valparaíso, principal praça comercial da república. Endurecido pelo suicídio do antigo comandante, Méndez y Nuñez exigia ainda a devolução da galeota capturada e de toda sua tripulação (Colson, 1882, p. 367-402).

Ainda no Chile, Varnhagen obrava constantemente para manejar a imagem do Império, arranhada pela declaração oficial de neutralidade e pela guerra no Paraguai. Jornais chilenos e peruanos republicavam matérias de periódicos argentinos afirmando ter o Brasil escravizado as tropas paraguaias derrotadas. Varnhagen então enviou um extenso ofício ao ministro Covarrubias desmentindo tais fatos, ${ }^{42}$ e comunicava ao Rio de Janeiro que:

Creio haver conseguido esclarecer bastantemente nesta República a opinião dos de boa-fé acerca dos assumptos do Paraguai; e melhor ficará sem dúvida, quando o sistema de completa publicidade aqui seguido, a minha nota 9 do corrente for impressa.43

No início de março regressou ao Peru para realizar a mesma tarefa.

Em 27 de março de 1866 o comandante espanhol enviou novo ultimatum ao governo chileno exigindo: 1- Uma declaração do governo chileno assumindo que havia sido sua intenção ofender à Espanha; 2- Devolução da Covadonga com bandeira, armamento e tripulação; 3- Saudação recíproca de 21 cañonazos, iniciado pelas baterias chilenas. Essas disposições consideradas humilhantes foram rechaçadas, e a esquadra espanhola preparou-se para a retaliação. Em 31 de março de 1866 a esquadra espanhola bombardeou o porto indefeso de Valparaíso.

\footnotetext{
${ }^{42}$ Ofício de 12/02/1866, de Francisco Adolfo de Varnhagen ao sr. José Antônio Saraiva. Missão Varnhagen Vol II Anexo II, p. 27-30.

${ }^{43}$ Idem, p. 33.
} 
Ao aportar em Valparaíso no dia 11 de abril, relatava ao Rio de Janeiro o ocorrido:

Acabo de chegar a esta cidade, encontrando ainda nela fumegantes as cinzas do incêndio lançado pelas forças bloqueadoras, sem gloria nem proveito para a Espanha, com pouca perda para o Chile, muita para os comerciantes estrangeiros, e muitíssima para os que aconselharam e resolveram semelhante providencia, que acarretará novas execrações e ódios irreconciliáveis da parte destas Repúblicas contra a Metrópole. ${ }^{44}$

A resposta do governo imperial foi enviada à Madri em 22 de maio de 1866. No despacho o governo imperial reiterava sua neutralidade, porém lamentando profundamente o ocorrido:

Este ato de excessiva e desnecessária hostilidade produz no Brasil a mais penosa impressão.

Neutro na guerra em que infelizmente se acham empenhado o Chile e a Espanha tem o Governo de S.M. O Imperador cumprido e cumprirá o mais religioso escrúpulo, os deveres que esta posição lhe impõe. Mas a par destes deveres tem ele outros que deve satisfazer, não somente no interesse próprio, como no dos demais Estados Americanos e no de uma causa que é comum a toda as nações civilizadas, sejam elas beligerantes ou neutras. ${ }^{45}$

Após o bombardeio a esquadra espanhola se dirigiu para o Peru. Em 26 de abril, estacionou em frente ao porto de Callao a uma prudente distância. Méndez y Nuñez intencionava bombardear o porto peruano, utilizando para isso toda sua força bélica, composta de sete embarcações de guerra. O comandante espanhol programou o bombardeio para o dia dois de maio, 51ㅇaniversário do levante espanhol contra as tropas napoleônicas (Rodriguez, 2003: 177).

Ao contrário de Valparaíso, Callao era uma praça fortificada contando com extensas baterias litorâneas. $\mathrm{O}$ governo peruano realizou preparativos de guerra melhorando as defesas e instalando novos e poderosos canhões Armstrong de $300 \mathrm{lb}$ e Blakely de $450 \mathrm{lb}$. Méndez y Nuñez afirmara em nota ao corpo diplomático acreditado em Lima que o bombardeio se daria em retaliação à quebra do tratado Vivanco-Pareja, concedendo quatro dias para evacuação da cidade e hasteamento de bandeira branca em edifícios beneficentes, hospitais e orfanatos (Colson, 1882: 436).

Situado no Chile, Varnhagen noticiou o combate de Callao em ofício de 14 de maio de 1866. Segundo o diplomata brasileiro, ouvindo relatos de estrangeiros concluiu que as perdas maiores foram espanholas, tendo os peruanos contado com 200 baixas, dentre elas o ministro peruano das finanças José Galvez Egúsquiza. ${ }^{46}$ As informações de Varnhagen, recebidas por carta do ministro americano Nelson, corroboram a historiografia peruana

\footnotetext{
${ }^{44}$ Idem, p. 69.

45 Despacho de 15/05/1866, de José Antônio Saraiva ao sr. Antônio José Duarte de Araújo Gondim. Missão Varnhagen Vol II, p. 216-218.

${ }^{46}$ Ofício de 14/05/1866, de Francisco Adolfo de Varnhagen ao sr. Antônio José Antônio Saraiva. Missão Varnhagen, Vol II, p. 84-85.
} 